\title{
Editorial: Tropical Climate Variability and Change: Impacts in the Amazon
}

\author{
Juan Carlos Jimenez ${ }^{1 *}$ and Ken Takahashi ${ }^{2}$ \\ ${ }^{1}$ Image Processing Laboratory, University of Valencia, Valencia, Spain, ${ }^{2}$ Servicio Nacional de Meteorología e Hidrología del \\ Perú (SENAMHI), Lima, Peru
}

Keywords: Amazon, tropical climate, climate change, ENSO (EI Nino/Southern Oscillation), drought

\section{Editorial on the Research Topic}

\section{Tropical Climate Variability and Change: Impacts in the Amazon}

Vast amounts of data from satellites and ground-based systems, and improvements on modeling techniques, allows a better understanding of Earth processes and advances on climate science. The tropics play a key role on global climate processes, and the tropical forest is a sensitive biome in the global hydrological and carbon cycles. In particular, the Amazon region includes about one half of the world's tropical forest, and relatively small change in Amazon forest dynamics have the potential to substantially affect the rate of climate change. This Research Topics focus on recent finding on the impacts of tropical climate variability and change over the Amazon ecosystem using satellite data, ground-based measurements or reanalysis climate data.

Droughts are one of the main features of the Amazon climate, and most contributions to this Research Topic have focused on the analysis of recent droughts through different perspectives. The El Niño Southern Oscillation (ENSO) is one of the main drivers of climatic variability over Amazonia, and it is linked to severe droughts, especially over the Brazilian Amazon. Widespread droughts have been also observed recently linked to anomalous high temperatures in the Tropical Atlantic. Recent severe drought events over Amazonia include those linked to the anomalous warm temperatures over the Tropical Atlantic in 2005 and 2010, and the very strong El Niño in 2015/16. Spatial and temporal patterns of these recent drought episodes have been usually addressed from temperature and precipitation datasets. Jimenez et al. provide a description of these three events from analysis of total cloud cover anomalies. A West-East pattern was found in total cloud cover anomalies mainly linked to El Niño events, whereas a North-South pattern was found to be linked to warm anomalies in the Tropical North Atlantic. Overall, long-term trends indicate a decrease in total cloud cover over southern Amazonia during the dry season, in contrast to the significant increasing trend found over northern Amazonia.

Fire responses to drought is another characteristic feature of Amazonia, leading to significant environmental, social, and economic impacts. Silva Junior et al. address this issue for the 2010 and 2015/16 droughts. Their findings evidence a greater intensity and extent of the 2015/16 drought compared to the 2010 drought, both in terms of rainfall deficits and warm temperatures. These two droughts emitted together $0.47 \mathrm{Pg} \mathrm{CO}_{2}$, but the 2015/16 emissions occurred mainly during the wet season.

The drought of 2015/16 is also addressed by Sun et al. using evapotranspiration data obtained from combined precipitation, gravity, and river discharge data. The study is complemented through analysis of Solar Induced Fluorescence (SIF) anomalies. The authors report negative ET and SIF anomalies for most of the Amazon basin during the 2015/16 El Niño event suggesting downregulation of productivity as a main factor of positive carbon flux anomalies during hot and dry conditions. 
Other contribute to a global understanding of the Amazonian climate. Fauset et al. use a recently developed model (Traitbased Forest Simulator-TFS) to explore the roles of climate and plant traits in controlling forest productivity and structure. Their findings suggest that climate controls the productivity of Amazon forests while traits control demography.

The authors also highlight that future model developments should focus on improving allocation, mortality, organ respiration, and simulation of understory trees and adding hydraulic traits.

Marengo et al. provide a review of the recent progress in understanding climate variability and trends in the Amazon region, with interest in the interaction with land use change. This study reveals that future sustainability of the Amazonian forests and its many services requires management strategies that consider the likelihood of multi-year droughts superimposed on a continued warming trend. It also highlights the role of deforestation control in support of policy for mitigation options as established in the Paris Agreement of 2015.

The potential of remote sensing techniques for a better understanding of the Amazon forests seasonality is explored by Franch et al. Earth Observation sensors on board the European Sentinel-2 satellite and American satellite Landsat are combined to improve vegetation reflectance estimations at high spatial resolution. These improvements have implications for the analysisof NDVI variations due to actual changes in the vegetation phenology, in contrast to variations due to contamination of the signal due to atmospheric perturbation or observation geometry.

In summary, the study of droughts over Amazonia has received increased interest in recent years because of environmental, social and economic impacts, and the role of recent droughts on the atmospheric $\mathrm{CO}_{2}$ growth rate. Droughts in 2005 and 2010, and especially the drought during the El Niño in 2015/16, occurred in an era with complete datasets for the monitoring of these events and subsequent impacts, which contributes to our current understanding of this phenomena.

\section{AUTHOR CONTRIBUTIONS}

All authors listed have made a substantial, direct and intellectual contribution to the work, and approved it for publication.

Conflict of Interest Statement: The authors declare that the research was conducted in the absence of any commercial or financial relationships that could be construed as a potential conflict of interest.

Copyright (๑) 2019 Jimenez and Takahashi. This is an open-access article distributed under the terms of the Creative Commons Attribution License (CC BY). The use, distribution or reproduction in other forums is permitted, provided the original author(s) and the copyright owner(s) are credited and that the original publication in this journal is cited, in accordance with accepted academic practice. No use, distribution or reproduction is permitted which does not comply with these terms. 